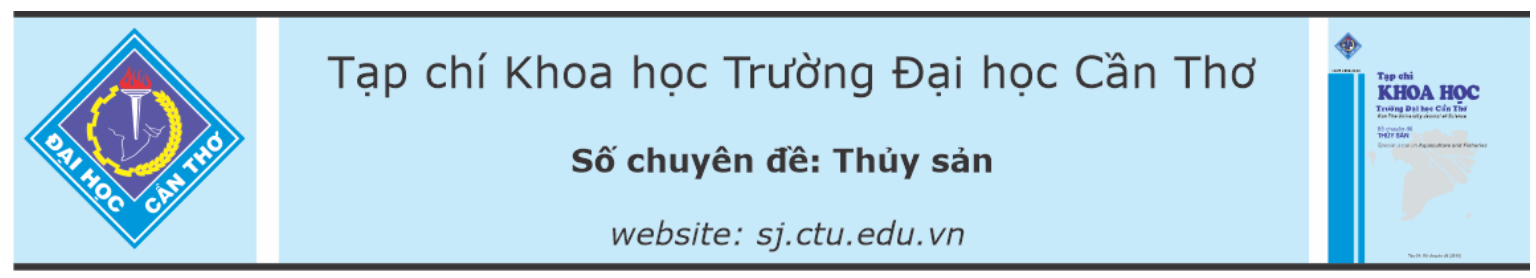

DOI:10.22144/ctu.jvn.2021.059

\title{
ẢNH HỬ̛̉ng CỦA MẬT Độ LÊN TĂNG TRƯởNG VÀ TỶ Lệ SỐNG CỦA CÁ CHIM VÂY VÀNG (Trachinotus blochii) GIỐNG ƯONG TRONG HỆ THỐNG TUẦN HOÀN
}

\author{
Lý Văn Khánh*, Cao Mỹ Án và Trần Ngọc Hải
}

Khoa Thủy sản, Truờng Đại học Cần Tho

*Nguoòi chịu trách nhiệm về bài viết: Lý Văn Khánh (email: lvkhanh@ctu.edu.vn)

\section{Thông tin chung:}

Ngày nhận bài: $22 / 02 / 2021$

Ngày nhận bài sủa: 21/05/2021

Ngày duyệt đăng: 01/06/2021

\section{Title:}

Effects of different densities on growth and survival rate of pompano (Trachinotus blochii) fingerlings reared in circulating water system

\section{Tù khóa:}

Cá chim vây vàng, hệ thống tuần hoàn, mật độ

\section{Keywords:}

Circulating water system, density, pompano

\begin{abstract}
This experiment on nursing of pompano (Trachinotus blochii) fish fingerlings at different stocking densities in recirculating water system was conducted at the College of Aquaculture and Fisheries, Can Tho University from December 2018 to January 2019. The experiment had four treatments with different densities of 60; 90; 120 and 150 individuals $/ \mathrm{m}^{3}$ and was designed with 3 replications. Pompano fingerlings with initial body weight of $2 \mathrm{~g}$ were reared in 500-L plastic tanks at water salimity of $20 \%$ and were continuously aerated. Fish were daily fed with pelleted feed (44\% protein) at rate of $15 \%$ total body weight. After 30 days of rearing, treatment with 150 individuals $/ \mathrm{m}^{3}$ showed the best results in growth rate $(0,26 \mathrm{~g} /$ day and 5,30\%/day) and was significantly higher than those of the other treatments $(p<0,05)$. The treatment with 60 individuals $/ \mathrm{m}^{3}$ showed the lowest results in growth rate $(0,20 \mathrm{~g} /$ day and 4,62 \%/day). Survival rate reached $100 \%$ at all treatments. Rearing pompano in the recirculating aquaculture system gave the best results at stocking density 150 individuals $/ \mathrm{m}^{3}$.
\end{abstract}

\section{TÓM TÁ́T}

Thi nghiệm uoong cá chim vây vàng (Trachinotus blochii) với các mật độ khác nhau trong hệ thống nước lọc tuần hoàn được thục hiện trại thực nghiệm của Bộ môn Kỹ thuật nuôi Hải sản, Khoa Thủy sản, Truờng Đại học Cần Tho tù tháng 12/2018 đến tháng 01/2019. Thi nghiệm gồm 4 nghiệm thức mật độ khác nhau: (1) $60 \mathrm{con} / \mathrm{m}^{3}$, (2) $90 \mathrm{con} / \mathrm{m}^{3}$, (3) $120 \mathrm{con} / \mathrm{m}^{3}$ và (4) $150 \mathrm{con} / \mathrm{m}^{3}$, mỗi nghiệm thức lạ̣p lại 3 lần. Cá chim vây vàng giống có khối lượng trung bình ban đầu $2 \mathrm{~g} /$ con được bố tri uoong trong bể nhưa $500 \mathrm{~L}$ với hệ thống nước lọc tuần hoàn, độ mặn 20\%o và sục khi liên tuc. Cá được cho ăn thức ăn công nghiệp hàm luợng đạm 44\% (thức ăn dành cho cá chẽm) và được điều chỉnh theo nhu cầu ở tất cả các nghiệm thức. Kết quả sau 30 ngày ương, tốc độ tăng trưởng của cá ở nghiệm thức mật độ $150 \mathrm{con} / \mathrm{m}^{3}$ (0,26 g/ngày và $\left.5,30 \% / n g a ̀ y\right)$ cao nhất và khác biệt có ý nghĩa thống kê $(p<0,05)$ so với ba nghiệm thức còn lại. Nghiệm thức mật độ $60 \mathrm{con} / \mathrm{m}^{3}$ (0,20 g/ngày và 4,62\%/ngày) thấp nhất khác biệt có ý nghĩa thống kê so với các nghiệm thức khác $(p<0,05)$. Tỷ lệ sống đạt 100\% ở tất cả các nghiệm thức khác biệt không có ý nghĩa thống kê $(p<0,05)$. Uơng cá chim vây vàng trong hệ thống nước lọc tuần hoàn tốt nhất khi ương với mật độ $150 \mathrm{con} / \mathrm{m}^{3}$. 


\section{GIỚI THIÊU}

Nuôi trồng thủy sản là một trong những ngành kinh tế trọng điểm của nước ta, đặc biệt là nuôi tôm và cá tra xuất khẩu. Tuy nhiên, nghề nuôi cũng gặp nhiều thách thức trước biến đổi khí hậu, môi trường, giá cả,... Vì thế, nghiên cứu phát triển đa dạng đối tượng nuôi và mô hình nuôi là rất cần thiết, đặc biệt là hướng nuôi nước lợ và nuôi biển. Trong số nhiều đối tượng tiềm năng, cá chim vây vàng (Trachinotus blochii) đã bước đầu được nghiên cứu và rất triển vọng. Đây là loài cá có tốc độ tăng trưởng nhanh, dễ nuôi, có thể phát triển với quy mô công nghiệp nuôi lồng hoặc trong ao đất ở các thủy vực nước lợ và nước mặn; có giá trị kinh tế, được thị trường trong và ngoài nước ưa chuộng (Ngọc Thúy, 2014). Hiện nay cá chim vây vàng đã được sản xuất giống nhân tạo thành công ở một số tỉnh như Khánh Hòa, Nghệ An, Quảng Ninh,... để cung cấp cho nhu cầu của người nuôi trên cả nước. Trong ương nuôi, sinh trưởng và tỷ lệ sống của cá phụ thuộc vào nhiều yếu tố: môi trường nước, mật độ, dinh dưỡng, hệ thống hoặc mô hình nuôi. Tuy nhiên, các nghiên cứu về mật độ ương cá chim vây vàng còn hạn chế (Ngô Vĩnh Hạnh, 2008). Trong xu hướng phát triển thủy sản hiện đại, ương nuôi cá và thủy sản nói chung trong hệ thống tuần hoàn là rất cần thiết nhằm nằng nâng cao năng suất, đảm bảo thân hiện môi trường, an toàn sinh học và chất lượng sản phẩm. Vì thế, nghiên cứu được thực hiện nhằm xác định mật độ thích hợp và góp phần xây dựng qui trình ương nuôi cá chim vây vàng trong hệ thống tuần hoàn.

\section{NÔI DUNG VÀ PHƯƠNG PHÁP NG̈HIÊN CÚU}

\subsection{Thời gian và địa điểm thực hiện}

Thí nghiệm được thực hiện từ tháng 12/2018 đến 01/2019 tại trại thực nghiệm của Khoa Thủy Sản, Trường Đại học Cần Thơ.

\subsection{Phương pháp nghiên cứu}

Thí nghiệm được bố trí ngẫu nhiên gồm 4 nghiệm thức mật độ cá ương khác nhau lần lượt là $60,90,120$ và $150 \mathrm{con} / \mathrm{m}^{3}$, mỗi nghiệm thức được lặp lại 3 lần. Cá chim vây vàng giống nhân tạo (được vận chuyển từ trại sản xuất giống ở Khánh Hòa về Cần Thơ) có khối lượng trung bình ban đầu $2,00 \pm 0,17 \mathrm{~g} / \mathrm{con}$ được bố trí vào bể ương có thể tích nước $500 \mathrm{~L}$ với độ mặn 20\%o. Thời gian thí nghiệm 30 ngày.

Hệ thống ương được lắp theo hệ thống tuần hoàn nước gồm bể ương có thể tích $500 \mathrm{~L}$, bể lắng $100 \mathrm{~L}$ và bể giá thể $200 \mathrm{~L}$ (giá thể chiếm $1 / 3$ thể tích bể).
Nước từ bể ương sẽ lưu thông qua bể lắng rồi qua bể giá thể sau đó nước được bơm trở về bể ương. Tốc độ lưu thông nước khoảng $100 \%$ thể tích bể ương mỗi ngày. Trong thời gian ương, bể ương và bể giá thể được sục khí liên tục.

Cá chim vây vàng giống được cho ăn thức ăn công nghiệp dạng viên nổi có hàm lượng đạm $44 \%$, cá được cho ăn 4 lần/ ngày ( $7 \mathrm{~h}, 10 \mathrm{~h}, 14 \mathrm{~h}$ và̀ $17 \mathrm{~h})$ và được cho ăn theo nhu cầu với lượng thức ăn khoảng $15 \%$ khối lượng lượng thân ở tất cả các nghiệm thức. Trong thời gian ương, lượng thức ăn cho cá ăn từng bể được ghi nhận mỗi ngày. Độ mặn nước của các bể ương được duy trì ở mức 20\%. Định kỳ siphon và bổ sung nước 1 tuần/lần.

Nhiệt độ và $\mathrm{pH}$ được đo 3 ngày/lần (7h và $14 \mathrm{~h})$ bằng máy đo $\mathrm{pH}$, hàm lượng $\mathrm{TAN}, \mathrm{NO}_{2}{ }^{-}$và độ kiềm được đo 6 ngày/lần bằng bộ test sera.

Mẫu cá ban đầu được cân khối lượng và đo chiều dài ngẫu nhiên 30 con để tính chung cho tất cả các nghiệm thức. Kết thúc thí nghiệm cá được cân khối lượng, đo chiều dài ngẫu nhiên của $30 \mathrm{con} / \mathrm{bể}$ và đếm số lượng cá trong từng bể của từng nghiệm thức để xác định tốc độ tăng trưởng, tỷ lệ sống.

Các chỉ tiêu về tốc độ tăng trưởng, tỷ lệ sống, hệ số phân cỡ và hệ số thức ăn được xác định theo các công thức sau:

Tốc độ tăng trưởng khối lượng tuyệt đối (g/ngày) $=\left(\mathrm{W}_{\mathrm{t}}-\mathrm{W}_{0}\right) / \mathrm{t}$

Tốc độ tăng trưởng khối lượng tương đối $(\% /$ ngày $)=100 *\left(\operatorname{LnW}_{\mathrm{t}}-\mathrm{LnW}_{0}\right) / \mathrm{t}$

Trong đó: $\mathrm{W}_{0}$ : Khối lượng cá ban đầu $(\mathrm{g})$

$\mathrm{W}_{\mathrm{t}}$ : Khối lượng kết thúc thí nghiệm $(\mathrm{g})$

t: Thời gian thí nghiệm (ngày)

Tốc độ tăng trưởng chiều dài tuyệt đối ( $\mathrm{cm} / \mathrm{ngày)}$ $=\left(\mathrm{L}_{\mathrm{t}}-\mathrm{L}_{0}\right) / \mathrm{t}$

Tốc độ tăng trưởng chiều dài tương đối (\%/ngày) $=100 *\left(\operatorname{LnL}_{\mathrm{t}}-\mathrm{LnL}_{0}\right) / \mathrm{t}$

Trong đó: $\mathrm{L}_{0}$ : Khối lượng cá ban đầu $(\mathrm{g})$

$\mathrm{L}_{\mathrm{t}}$ : Khối lượng kết thúc thí nghiệm $(\mathrm{g})$

t: Thời gian thí nghiệm (ngày)

Tỷ lệ sống $(\%)=100 *$ (số cá thu hoạch)/ (số cá thả ban đầu)

Hệ số phân cỡ: $\mathrm{CV}=\frac{S}{\bar{X}} * 100$

Trong đó: S: Độ lệch chuẩn 
$\bar{X}$ : Khối lượng trung bình của cá

Hệ số tiêu hóa thức ăn: FCR= thức ăn cho ăn (g)/trọng lượng vật nuôi (g)

\subsection{Phương pháp phân tích và xử lý số liệu}

Tất cả các số liệu thu được sẽ được tính toán các giá trị trung bình, độ lệch chuẩn và phân tích phương sai ANOVA một nhân tố, phép thử Duncan để tìm ra sự khác biệt giữa các giá trị trung bình của các nghiệm thức, sử dụng phần mềm SPSS để xử lý thống kê ở mức ý nghĩa $(\mathrm{p}<0,05)$.

\section{KẾT QUẢ VÀ THẢO LUẬN}

\subsection{Các yếu tố môi trường nước}

Trong thời gian thí nghiệm, nhiệt độ nước trong bể ương tương đối ổn định. Nhiệt độ trung bình trong các bể dao động từ $26-27,5^{\circ} \mathrm{C}$, nhiệt độ thấp nhất là $26,1^{\circ} \mathrm{C}$, cao nhất $27,5^{\circ} \mathrm{C}$. Theo Cheng (1990), nhiệt độ từ $16-36^{\circ} \mathrm{C}$ cá phát triển bình thường và sinh trưởng tốt $22-28^{\circ} \mathrm{C}$. Nhìn chung nhiệt độ nước trong bể ương thích hợp cho sinh trưởng và phát triển của cá.

Bảng 1. Các yếu tố thủy lý trong thời gian thí nghiệm

\begin{tabular}{ccrrr}
\hline $\begin{array}{c}\text { Nghiệm thức } \\
\left.\text { (con/ } \mathbf{m}^{\mathbf{3}}\right)\end{array}$ & \multicolumn{2}{c}{ Nhiệt độ $\left({ }^{\mathbf{0}} \mathbf{C}\right)$} & \multicolumn{2}{c}{$\mathbf{p H}$} \\
\cline { 2 - 5 } & $\mathbf{7 ~ g i o ̛ ̀ ~}$ & $\mathbf{1 4}$ giờ & $\mathbf{7}$ giờ & $\mathbf{1 4}$ giò̀ \\
\hline 60 & $26,2 \pm 0,09$ & $27,5 \pm 0,10$ & $8,0 \pm 0,09$ & $8,0 \pm 0,07$ \\
90 & $26,2 \pm 0,13$ & $27,4 \pm 0,25$ & $7,9 \pm 0,00$ & $7,9 \pm 0,02$ \\
120 & $26,1 \pm 0,05$ & $27,2 \pm 0,14$ & $7,9 \pm 0,07$ & $7,9 \pm 0,06$ \\
150 & $26,2 \pm 0,06$ & $27,3 \pm 0,17$ & $7,9 \pm 0,08$ & $7,8 \pm 0,09$ \\
\hline
\end{tabular}

Theo Boyd (1998), pH nước thích hợp cho sự phát triển của cá khoảng từ $6,5-9,0 \mathrm{pH}$ quá thấp hoặc quá cao cũng ảnh hưởng đến sinh trưởng và sinh sản cá. pH ghi nhận trong quá trình thí nghiệm dao động từ 7,8-8,0 là khoảng thích hợp cho các loài cá sinh trưởng và phát triển bình thường.

Biến động của TAN khác nhau ở các nghiệm thức, dao động trung bình từ $0,17-0,25$ (mg/l) (Bảng
2). Hầu hết ở các đợt thu mẫu thì hàm lượng TAN cao nhất ở nghiệm thức ương cá ở mật độ 150 $\mathrm{con} / \mathrm{m}^{3}$ do số lượng cá nhiều nên lượng chất thải cũng nhiều hơn và hàm lượng TAN cao hơn so với các mật độ khác. Nồng độ TAN thích hợp cho cá chim vây vàng là $<1 \mathrm{mg} / \mathrm{l}$. Hàm lượng $\mathrm{TAN}$ thích hợp cho ao nuôi thủy sản là từ $0,2-2 \mathrm{mg} / 1$ (Boyd, 1998). Do đó hàm lượng TAN trong bể ương không gây ảnh hưởng đến sinh trưởng của cá.

Bảng 2. Các yếu tố thủy hóa trong thời gian thí nghiệm

\begin{tabular}{crrr}
\hline Nghiệm thức $\left(\mathbf{c o n} / \mathbf{m}^{\mathbf{3}}\right)$ & $\mathbf{T A N}(\mathbf{m g} / \mathbf{L})$ & $\mathbf{N O}_{2}^{-}(\mathbf{m g} / \mathbf{L})$ & Độ kiềm $\mathbf{~} \mathbf{m g ~} \mathbf{C a C O} / \mathbf{L})$ \\
\hline 60 & $0,22 \pm 0,05$ & $0,22 \pm 0,10$ & $110 \pm 3,33$ \\
90 & $0,17 \pm 0,00$ & $0,75 \pm 0,44$ & $87,8 \pm 5,09$ \\
120 & $0,19 \pm 0,17$ & $0,97 \pm 0,13$ & $85,6 \pm 3,85$ \\
150 & $0,25 \pm 0,08$ & $1,22 \pm 0,17$ & $78,9 \pm 13,88$ \\
\hline
\end{tabular}

Theo Bảng 2, hàm lượng $\mathrm{NO}_{2}^{-}$trung bình dao động trong khoảng $0,22-1,22(\mathrm{mg} / \mathrm{L})$, nồng độ này ở nhiệt độ trung bình trong các bể dao động từ 26$27,5^{\circ} \mathrm{C}$ nên không gây độc cho cá. Nghiệm thức có hàm lượng $\mathrm{NO}_{2}^{-}$cao nhất là mật độ $150 \mathrm{con} / \mathrm{m}^{3}$ $(1,22 \mathrm{mg} / \mathrm{L})$ và thấp nhất là $60 \mathrm{con} / \mathrm{m}^{3}(0,22 \mathrm{mg} / \mathrm{L})$. Do số lượng cá ở nghiệm thức $150 \mathrm{con} / \mathrm{m}^{3}$ nhiều nên lượng chất thải cũng cao hơn. Theo Boyd (1998), hàm lượng nitrite thích hợp cho ao nuôi thủy sản nói chung nhỏ hơn 4,5 mg/L.

Như vậy, sự biến động $\mathrm{NO}_{2}{ }^{-}$của các nghiệm thức trong các đợt thu mẫu nằm trong khoảng cho phép nên không ảnh hưởng đến tốc độ tăng trưởng và tỉ lệ sống của cá chim vây vàng.

Độ kiềm của các nghiệm thức biến động khác nhau, giai đoạn đầu kiềm cao hơn giai đoạn sau trong quá trình ương nuôi. Ion bicarbonate và carbonate là nguồn carbon cung cấp cho quá trình phát triển các tế bào vi khuẩn trong hệ thống lọc tuần hoàn. Vì vậy giai đoạn đầu hệ thống lọc giá thể mới hoạt động, lượng vi khuẩn lọc chưa phát triển nhiều nên chưa sử dụng nhiều kiềm trong nước, khi hệ thống lọc ổn định lượng vi khuẩn phát triển nhiều, độ kiềm trong nước có xu hướng giảm.

\subsection{Tăng trưởng về khối lượng của cá}

Bảng 3 cho thấy nghiệm thức ương với mật độ $150 \mathrm{con} / \mathrm{m}^{3}$ cá tăng trưởng nhanh nhất về khối lượng, khối lượng trung bình ban đầu của cá là $2,00 \pm 0,17 \mathrm{~g} / \mathrm{con}$. Sau 30 ngày nuôi, cá đạt khối lượng trung bình $9,83 \mathrm{~g} / \mathrm{con}$, khác biệt có ý nghĩa thống kê $(\mathrm{p}<0,05)$ so với các nghiệm thức mật độ ương khác trong thí nghiệm. 
Sau 30 ngày ương, tốc độ tăng trưởng tuyệt đối ở nghiệm thức ương cá ở mật độ $150 \mathrm{con} / \mathrm{m}^{3}$ là nhanh nhất $0,26 \mathrm{~g} /$ ngày khác biệt có ý nghĩa thống kê $(\mathrm{p}<0,05)$ so với các nghiệm thức mật độ ương khác. Tốc độ tăng trưởng tuyệt đối chậm nhất là ở nghiệm thức mật độ $60 \mathrm{con} / \mathrm{m}^{3}(0,20 \mathrm{~g} /$ ngày $)$, khác biệt không có ý nghĩa thống kê với hai nghiệm thức ương $90 \mathrm{con} / \mathrm{m}^{3}$ và $120 \mathrm{con} / \mathrm{m}^{3}$. Tốc độ tăng trưởng khối lượng tương đối ở nghiệm thức $150 \mathrm{con} / \mathrm{m}^{3}$ nhanh nhất (5,30\%/ngày) khác biệt có ý nghĩa thống kê $(\mathrm{p}<0,05)$ với các nghiệm thức khác trong thí nghiệm.

Bảng 3. Tăng trưởng về khối lượng của cá sau 30 ngày ương

\begin{tabular}{crrrr}
\hline \multirow{2}{*}{$\begin{array}{c}\text { Nghiệm thức } \\
\left(\mathbf{c o n} / \mathbf{m}^{\mathbf{3}}\right)\end{array}$} & \multicolumn{2}{c}{ Khối lượng (g/con) } & \multicolumn{2}{c}{ Tốc độ tăng trưởng khối lượng } \\
\cline { 2 - 5 } & Ban đầu & $\mathbf{3 0}$ ngày & Tuyệt đối (g/ngày) & Tương đối (\%/ngày) \\
\hline 60 & $2,00 \pm 0,17$ & $8,02 \pm 0,63^{\mathrm{a}}$ & $0,20 \pm 0,02^{\mathrm{a}}$ & $4,62 \pm 0,26^{\mathrm{a}}$ \\
90 & $2,00 \pm 0,17$ & $8,72 \pm 0,51^{\mathrm{a}}$ & $0,22 \pm 0,02^{\mathrm{a}}$ & $4,91 \pm 0,19^{\mathrm{a}}$ \\
120 & $2,00 \pm 0,17$ & $8,53 \pm 0,63^{\mathrm{a}}$ & $0,22 \pm 0,02^{\mathrm{a}}$ & $4,83 \pm 0,25^{\mathrm{a}}$ \\
150 & $2,00 \pm 0,17$ & $9,83 \pm 0,66^{\mathrm{b}}$ & $0,26 \pm 0,02^{\mathrm{b}}$ & $5,30 \pm 0,23^{\mathrm{b}}$ \\
\hline
\end{tabular}

Các số liệu trong cùng một cột có chũ cái khác nhau thì khác biệt có ý nghĩa thống kê (p<0,05).

\subsection{Tăng trưởng về chiều dài của cá}

Bảng 4 cho thấy tốc đô tăng trưởng ở nghiệm thức ương cá ở mật độ $150 \mathrm{con} / \mathrm{m}^{3}$ cá tăng trưởng nhanh nhất về chiều dài $(6,38 \mathrm{~cm})$ sau 30 ngày ương so với chiều dài ban đầu $3,81 \mathrm{~cm}$, khác biệt ý nghĩa thống kê $(\mathrm{p}<0,05)$ với các nghiệm thức còn lại. Tốc độ tăng trưởng về chiều dài chậm nhất ở nghiệm thức mật độ $60 \mathrm{con} / \mathrm{m}^{3}(5,97 \mathrm{~cm})$ khác biệt có ý nghĩa thống kê $(\mathrm{p}<0,05)$ so với nghiệm thức 150 $\mathrm{con} / \mathrm{m}^{3}$, khác biệt không có ý nghĩa thống kê với hai nghiệm thức ương $90 \mathrm{con} / \mathrm{m}^{3}$ và $120 \mathrm{con} / \mathrm{m}^{3}$.

Bảng 4. Tăng trưởng về chiều dài của cá sau 30 ngày ương

\begin{tabular}{crrrr}
\hline \multirow{2}{*}{$\begin{array}{c}\text { Nghiệm thức } \\
\left(\mathbf{c o n} / \mathbf{m}^{\mathbf{3}}\right)\end{array}$} & \multicolumn{2}{c}{ Chiều dài $(\mathbf{c m} / \mathbf{c o n})$} & \multicolumn{2}{c}{ Tốc độ tăng trưởng chiều dài } \\
\cline { 2 - 5 } & Ban đầu & $\mathbf{3 0}$ ngày & Tuyệt đối $\mathbf{( c m} / \mathbf{n g a ̀ y})$ & Tương đối $(\% / \mathbf{n g a ̀ y})$ \\
\hline 60 & $3,81 \pm 0,14$ & $5,97 \pm 0,01^{\mathrm{a}}$ & $0,07 \pm 0,003^{\mathrm{a}}$ & $1,50 \pm 0,05^{\mathrm{a}}$ \\
90 & $3,81 \pm 0,14$ & $6,12 \pm 0,14^{\mathrm{a}}$ & $0,08 \pm 0,005^{\mathrm{a}}$ & $1,58 \pm 0,07^{\mathrm{a}}$ \\
120 & $3,81 \pm 0,14$ & $6,09 \pm 0,10^{\mathrm{a}}$ & $0,08 \pm 0,003^{\mathrm{a}}$ & $1,56 \pm 0,06^{\mathrm{a}}$ \\
150 & $3,81 \pm 0,14$ & $6,38 \pm 0,15^{\mathrm{b}}$ & $0,09 \pm 0,005^{\mathrm{b}}$ & $1,72 \pm 0,08^{\mathrm{b}}$ \\
\hline
\end{tabular}

Các số liệu trong cùng một cột có chũ cái khác nhau thì khác biệt có ý nghĩa thống kê $(p<0,05)$.

Sau 30 ngày ương, tốc độ tăng trưởng tuyệt đối về chiều dài ở nghiệm thức mật độ cá $150 \mathrm{con} / \mathrm{m}^{3}$ là $0,09 \mathrm{~cm} /$ ngày, cao nhất và khác biệt ý nghĩa thống kê $(\mathrm{p}<0,05)$ so với các nghiệm thức còn lại. Ở nghiệm thức mật độ ương cá $60 \mathrm{con} / \mathrm{m}^{3}$ có tốc độ tăng trưởng về chiều dài chậm nhất $(0,07 \mathrm{~cm} /$ ngày) không khác biệt với các nghiệm thức với mật độ ương 90 và $120 \mathrm{con} / \mathrm{m}^{3}$. Tốc độ tăng trưởng tương đối về chiều dài của cá ương với mật độ $150 \mathrm{con} / \mathrm{m}^{3}$ là $1,72 \% /$ ngày, khác biệt có ý nghĩa thông kê $(\mathrm{p}<0,05)$ với ba nghiệm thức còn lại.

Kết quả Bảng 3 và Bảng 4 cho thấy cá chim vây vàng tăng trưởng nhanh nhất ở mật độ cao 150 $\mathrm{con} / \mathrm{m}^{3}$. Điều này có thể do cá chim vây vàng là loài cá sống bầy đàn, mật độ cao sẽ kích thích cá bắt mồi hiệu quả hơn và lớn nhanh hơn. Kết quả cũng cho thấy hệ thống tuần hoàn và lọc sinh học khá hiệu quả, nên mật độ chưa ảnh hưởng xấu đến môi trường và tăng trưởng của cá. Kết quả cũng đề xuất rằng mật độ ương có thể được nâng cao hơn. Theo Thân Thị Hằng và Đỗ Thị Hòa (2013), thí nghiệm ương cá chim vây vàng (Trachinotus Blochii) cỡ $3-4 \mathrm{~cm}$ bằng giai lưới đặt trong ao đất trong 4 tuần ở các mật độ khác nhau $\left(100,200,300,400,500 \mathrm{con} / \mathrm{m}^{3}\right)$ chỉ ra rằng mật độ ương có ảnh hưởng đến sinh trưởng của cá. Trong đó, mật độ ương 400-500 con/ $\mathrm{m}^{3}$ đạt kết quả tốt nhất $(8,66 \mathrm{~g}$ và $7,23 \mathrm{~g})$.

\subsection{Tỷ lệ sống và hệ số phân cỡ của cá sau 30 ngày ương}

Qua kết quả thống kê (Bảng 5), tỷ lệ sống của cá đạt $100 \%$ ở tất cả các nghiệm thức thí nghiệm. Điều này cho thấy mật độ ương không ảnh hưởng đến tỷ lệ sống của cá chim vây vàng. Cá có sức sống tốt, các yếu tố môi trường và thức ăn thí nghiệm phù hợp với sự phát triển của cá. Theo Chu Chí Thiết và ctv. (2010), ở giai đoạn cá hương, mật độ không ảnh hưởng đến tỷ lệ sống của cá chim vây vàng. 
Bảng 5. Tỷ lệ sống và hệ số phân cõ̃ của cá sau 30 ngày ương

\begin{tabular}{crrr}
\hline Nghiệm thức $\left(\mathbf{c o n} / \mathbf{m}^{\mathbf{3}}\right)$ & Tỷ lệ sống $\mathbf{( \% )}$ & Hệ số phân cỡ về khối lượng & FCR \\
\hline 60 & $100 \pm 0,00^{\mathrm{a}}$ & $1,56 \pm 0,19^{\mathrm{b}}$ & $1,21 \pm 0,051^{\mathrm{a}}$ \\
90 & $100 \pm 0,00^{\mathrm{a}}$ & $1,62 \pm 0,21^{\mathrm{b}}$ & $1,18 \pm 0,018^{\mathrm{a}}$ \\
120 & $100 \pm 0,00^{\mathrm{a}}$ & $1,53 \pm 0,16^{\mathrm{b}}$ & $1,23 \pm 0,043^{\mathrm{a}}$ \\
150 & $100 \pm 0,00^{\mathrm{a}}$ & $0,16 \pm 0,01^{\mathrm{a}}$ & $1,31 \pm 0,188^{\mathrm{a}}$ \\
\hline
\end{tabular}

Các số liệu trong cùng một cột có chũ cái khác nhau thì khác biệt có ý nghĩa thống kê $(p<0,05)$.

Theo Bảng 5 , hệ số tiêu hóa thức ăn của cá ở cả 4 nghiệm thức có giá trị gần bằng nhau, khác biệt không có ý nghĩa thống kê $(\mathrm{p}<0,05)$.

Hệ số phân cỡ thấp nhất là ở nghiệm thức ương cá ở mật độ $150 \mathrm{con} / \mathrm{m}^{3}(0,16)$ khác biệt có ý nghĩa thống kê $(\mathrm{p}<0,05)$ so với ba nghiệm thức khác trong thí nghiệm. Ba nghiệm thức 60,90 và $120 \mathrm{con} / \mathrm{m}^{3}$ có hệ số phân đàn gần bằng nhau, khác biệt không
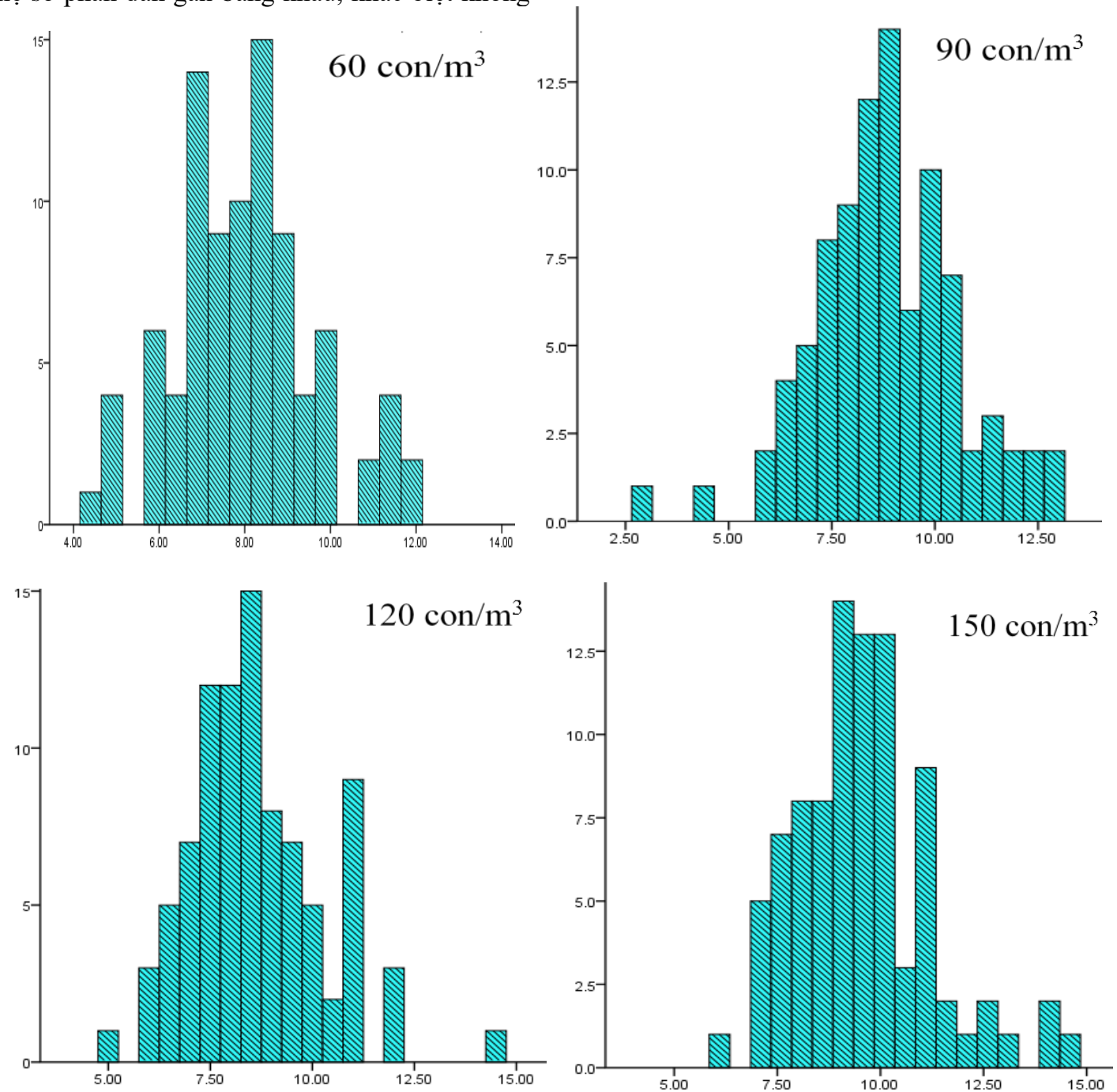

Hình 1. Sự phân cõ̃ về khối lượng của cá sau 30 ngày ương 


\section{KÊT LUẬN VÀ ĐỀ NGH!}

\subsection{Kết luận}

Kết quả thí nghiệm cho thấy ương cá chim vây vàng trong hệ thống tuần hoàn nước là rất tốt và mật độ $150 \mathrm{con} / \mathrm{m}^{3}$ cho kết quả tăng trưởng tốt nhất với khối lượng đạt $9,83 \mathrm{~g} / \mathrm{con}$, tốc độ tăng trưởng 0,26 $\mathrm{g} /$ ngày và $5,30 \% /$ ngày. Chiều dài của cá đạt 6,38 $\mathrm{cm} / \mathrm{con}$, tốc độ tăng trưởng $0,09 \mathrm{~cm} /$ ngày và $1,72 \%$ /ngày, tỷ lệ sống đạt $100 \%$ sau 30 ngày ương.

\section{2. Đề nghị}

Cần nghiên cứu ương cá chim vây vàng trong hệ thống tuần hoàn ở các mật độ cao hơn.

\section{LỜI CẢM ƠN}

Đề tài này được tài trợ bởi Dự án nâng cấp trường Đại học Cần Thơ VN14-P6 bằng nguồn vốn vay $\mathrm{ODA}$ từ Chính phủ nhật bản.

\section{TÀI LIỆU THAM KHẢO}

Boyd, C.E. (1998). Water quality in ponds for aquacuture. Research and Development, series No. 43. International Center for aquaculture \& aquatic environment. Alabama agricultural experiment station, Auburn University.

Chu Chí Thiết. (2010). Ảnh hưởng của độ mặn và mật độ urong nuôi cá chim vây vàng (Trachinotus blochii Lacepede, 1801) tù giai đoạn cá huong lên cá giống (Luận văn Thạc sĩ). Trường Đại học Nông nghiệp Hà Nội.

Lê Quốc Việt, Trần Ngọc Hải \& Nguyễn Anh Tuấn. (2010). Ảnh hưởng mật độ ương và thức ăn có hàm lượng protein khác nhau lên sự tăng trưởng và tỷ lệ sống của cá đối (Liza subviridis) từ giai đoạn cá hương lên giống. Tạp chí khoa học Đại học Cần Tho 2010, 15a, 189-197.

Ngô Vĩnh Hạnh. (2007). Dự án nhập công nghệ sản xuất giống cá chim vây vàng (Trachinotus blochii Lacepede, 1801). Báo cáo khoa học Trường $\mathrm{Cao}$ đẳng Thủy sản Bắc Ninh.

Ngọc Thúy. (2014). Sản xuất giống và nuôi thuoong phẩm cá chim vây vàng tại Việt Nam. Viện Nuôi trồng thủy sản, Trường Đại học Nha Trang.

Thân Thị Hằng \& Đỗ Thị Hòa. (2013). Ảnh hưởng của mật độ, loại thức ăn và khẩu phần ăn lên sinh trưởng, tỷ lệ sống của cá chim vây vàng (Trachinotus blochii Lacepede, 1801) giống ương bằng giai đặt trong ao đất. Tạp chi Khoa họ - Công nghệ Thủy sản Truòng Đại học Nha Trang, 3, trang 95-99.

Trần Ngọc Hải, Lý Văn Khánh, Lê Quốc Việt \& Nguyễn Thanh Phương. (2017). Kỹ thuật sản xuất giống và nuôi cá biển. Nhà xuất bản Đại học Cần Thơ. 